\title{
Cardioprotective and $\beta$-adrenoceptor
} antagonistic activity of a newly synthesized
aryloxypropanolamine derivative PP-36

This article was published in the following Dove Press journal:

Journal of Experimental Pharmacology

II February 2010

Number of times this article has been viewed

\author{
Lokesh K Bhatt ${ }^{\prime}$ \\ Jyotika Bansal ${ }^{2}$ \\ Poonam Piplani ${ }^{2}$ \\ SL Bodhankar ${ }^{3}$ \\ A Veeranjaneyulu' \\ 'Department of Pharmacology, \\ School of Pharmacy and Technology \\ Management, NMIMS University, \\ Mumbai, India; ${ }^{2}$ University Institute \\ of Pharmaceutical Sciences, Panjab \\ University, Chandigarh, India; \\ ${ }^{3}$ Department of Pharmacology, \\ Bharati Vidyapeeth Deemed \\ University, Poona College of \\ Pharmacy, Erandawane, Pune, India
}

Correspondence: A Veeranjaneyulu Department of Pharmacology, School of Pharmacy and Technology Management, NMIMS University, Mumbai, 400056, India $\mathrm{Tel}+912264521148$

Fax +9| 2226185422

Email add_bits@yahoo.com

\begin{abstract}
The present study was performed to evaluate the cardioprotective effects and pharmacological characterization of newly synthesized $\beta$-adrenoreceptor antagonists 3-(3-tertbutylamino-2-hydroxypropoxy)-4-methoxybenzaldehyde (PP-36) in the rat model of coronary artery occlusion and reperfusion. Pre-ischemic administration (20 minutes before coronary occlusion) of PP-36 showed cardioprotective effects against ischemia/reperfusion injury in rats. PP-36 (6 $\left.\mathrm{mg} \mathrm{kg}^{-1}\right)$ significantly reduced arrhythmia score $(6.33 \pm 0.55, P<0.05)$, infarct size/left ventricle size $(38.9 \pm 3.2, P<0.05)$ and no mortality compared to vehicle-treated control group ( $14.17 \pm 1.83,44.9 \pm 4.6$ and $17 \%$ respectively). In-vitro studies in rat isolated right atria, guinea-pig trachea and rat distal colon preparations, were carried out to investigate the potency of PP-36 towards different $\beta$-adrenoceptor subtypes. $\mathrm{pA}_{2} / \mathrm{pK}_{\mathrm{B}}$ values of PP-36 for $\beta_{1}-\beta_{2}$ - and $\beta_{3}$-adrenoceptors were $6.904 \pm 0.190,6.44 \pm 0.129$ and $5.773 \pm 0.129$, respectively. In conclusion, PP-36 is a $\beta$-adrenoceptor antagonist possessing potent anti-arrhythmic and cardioprotective effects against ischemia/reperfusion injury in rats.
\end{abstract}

Keywords: $\beta$-adrenoreceptors blocker, ischemia/reperfusion injury, arrhythmias, infarct area

\section{Introduction}

Cardiovascular diseases (CVD) are the leading cause of premature death in industrialized countries and its prevalence is increasing in the developing world. ${ }^{1}$ It affects the proper functioning of the heart and blood vessels, to mention a few important ones: myocardial infarction (MI); cerebrovascular diseases (stroke); transient ischemic attacks (TIA); hypertension; peripheral vascular diseases (PVDs); and coronary heart disease (CHD). ${ }^{2}$ The burden of death and disability due to CHD continues to increase ${ }^{3}$ and in the absence of suitable preventive efforts it is not controlled. ${ }^{4}$

High blood pressure is the most prevalent and modifiable risk factor for myocardial infarction, stroke, end-stage renal disease and PVD. It has been extensively demonstrated that the early screening and management of individuals with high blood pressure levels leads to a reduction in the occurrence of stroke and possibly myocardial infarction. ${ }^{5}$

Introduction of $\beta$-adrenoreceptor blockers (BABs) initiated a breakthrough in the treatment of various cardiovascular disorders in the last four decades. During the last few years $\beta$-adrenergic receptor antagonists have also been established in the treatment of congestive heart failure. In patients with myocardial infarction, hypertension, and in those with congestive heart failure, $\beta$-adrenergic receptor antagonists have been found to reduce mortality and morbidity. ${ }^{6}$ The favorable effects of $\beta$-adrenergic receptor antagonists may stem from decreased myocardial oxygen demand, redistribution

submit your manuscript $\mid$ www. dovepress.con 
of myocardial blood flow, reduction of the concentration of the free fatty acids in plasma and antiarrhythmic actions. $\beta$ blockers are now regarded as a first line choice of treatment in hypertension along with diuretics, by the Joint National Committee, ${ }^{7}$ the British Hypertensive Society, ${ }^{8}$ and a firstline alternative with various antihypertensives by the World Health Organization. These BABs may better control the increased blood pressure in response to hypoglycemia, exercise, or cigarette smoking. ${ }^{9}$ Non selective BABs may be preferably used to decrease epinephrine induced hypokalemia or to prevent myocardial infarction, and in certain circumstances migraine, anxiety, thyrotoxicosis or essential tremor. BABs with partial agonistic activity may theoretically cause a lesser degree of cardiodepression, bronchospasm, and peripheral vasoconstriction and minor effects on plasma lipids. ${ }^{10}$

The usefulness of $\beta$-adrenoreceptor antagonists in the treatment of various cardiovascular and non-cardiovascular complications prompted the present investigation to search for new $\beta$-adrenoreceptor antagonists. We have been involved in the development of new $\beta$ blockers for the past few years. ${ }^{11,15}$ The earlier works were based on the practolol structures by introducing a para-amidic functional group in the phenyl group. Recently we developed new compounds having ortho-methoxy group with meta- substitution to the phenyl group having the propanolamine group. In this study, we report the pharmacological investigation of the oxalate salt of 3-(3-tert-butylamino-2-hydroxypropoxy)-4-methoxybenzaldehyde (PP-36, Figure 1) for its $\beta$-adrenoceptor antagonistic activity and cardioprotective activity. PP-36 was synthesized at Department of Medicinal Chemistry, University Institute of Pharmaceutical Sciences, Panjab University, Chandigarh, India.

\section{Materials and methods}

\section{Animals}

Wistar rats (200-250 g) and Guinea Pig (300-350 g) were purchased from the National Toxicology Centre, Sinhagad Road, Pune, India and were housed at a temperature of

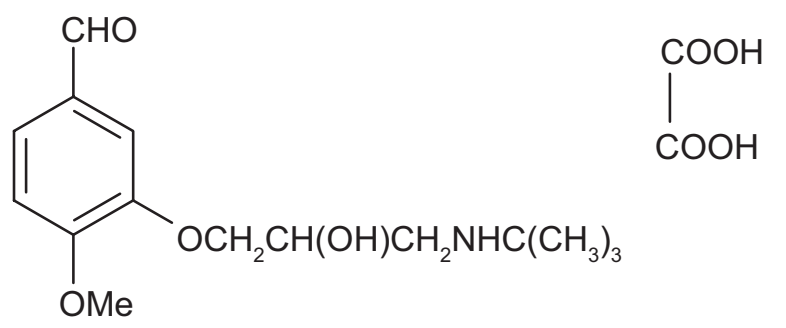

Figure I Structure of PP-36.
$25{ }^{\circ} \mathrm{C} \pm 1{ }^{\circ} \mathrm{C}$ and relative humidity of $45 \%$ to $55 \%$ in a clean environment under 12:12 hours light/dark cycle. The animals had free access to food pellets (Chakan Oil Mills, Pune, India) and filtered water was available ad libitum. The research protocol was approved by Institutional Ethical Committee (IEC) of Poona College of Pharmacy constituted under Committee for the Purpose of Control and Supervision of Experiments on Animals (IAEC Approval number: CPCSEA/05/15).

\section{Drugs}

The pharmacological agents used were isoprenaline hydrochloride (Sigma chemical Co., St. Louis, MO, USA), atenolol hydrochloride (Khandelwal Laboratory Ltd., Mumbai, India) and urethane (Fluka Chemika GmbH, Buchs, France). The drugs were dissolved and diluted to appropriate concentrations with physiological saline. Fresh drug solutions were prepared on the day of the experiment. Sodium chloride, potassium chloride, magnesium sulfate hepta-hydrate, potassium dihydrogen phosphate, calcium chloride, glucose and sodium bicarbonate all of analytical grade were purchased from S.D. Fine Chemicals Ltd., (Mumbai, India) and dissolved in distilled water for the preparation of physiological salt solution. PP-36 was dissolved in saline in different concentrations for all administrations.

\section{Acute intravenous toxicity study}

The acute intravenous toxicity study was conducted using preliminary limit dose test of the Up-and-Down Procedure statistical program-AOT 425StatPgm (2001).

\section{In vivo studies}

\section{Production of coronary ischemia/reperfusion injury in rats}

Male Wistar rats weighing 200-250 g were anesthetized by intraperitoneal injection of urethane $(1.20 \mathrm{~g} / \mathrm{kg})$ and the left coronary artery ligation was performed as reported earlier. ${ }^{16}$ Systemic blood pressure was monitored via a catheter inserted into the carotid artery. A standard limb lead I electrocardiogram (ECG) was continuously recorded, together with arterial pressure, on a recorder (MP30, BIOPAC System Inc., Santa Barbara CA, USA). Artificial ventilation was started with room air, using a tidal volume of $1.5 \mathrm{~mL} / 100 \mathrm{~g}$ and at a rate of 54 strokes/minute in order to maintain arterial blood gases and $\mathrm{pH}$ within the normal range. The chest was opened by a left thoracotomy, followed by sectioning of the 4th and 5 th ribs, approximately $2 \mathrm{~mm}$ to the left of the sternum. After incising the pericardium, the heart was exteriorized by using gentle pressure on the rib cage. A 4/0 nylon suture attached 
to a $14-\mathrm{mm}$ micropoint reverse cutting needle was placed under the left coronary artery.

The heart was put back in the chest, and the rat was allowed to stabilize. Thirty-minute regional myocardial ischemia was induced by pulling the two ends of the suture through a small plastic tube and pressing the tube against the surface of the myocardium and then clamping the tube together with the suture. Then, reperfusion was initiated by unclamping and removal of the tube. After reperfusion, the responses were observed for 120 minutes. Ischemia and reperfusion was confirmed as described previously. ${ }^{7}$ In brief, successful occlusion was confirmed by the increased amplitude of the $\mathrm{R}$ wave of lead I during the first few seconds of each occlusion, which has been demonstrated to be more useful than lead II or other ECG leads in rats, and a $20 \%-30 \%$ decline in the arterial blood pressure compared to the pre-ischemic values.

\section{Study group, experimental protocol and exclusion criteria}

Rats were randomly assigned to seven groups including one sham-operated group. All groups, other than the sham treated group, underwent a 30 minute coronary artery occlusion and a 2 hour reperfusion. The control group underwent saline infusion before 30 minute coronary artery occlusion and 2 hour reperfusion. Test drug PP-36 (1.0, 3.0, $6.0 \mathrm{mg} / \mathrm{kg})$ atenolol $(1 \mathrm{mg} / \mathrm{kg})$ were infused for 20 minutes before prolonged ischemia and reperfusion. Different doses of drugs were used to observe the dose-dependent effect of the drugs. For the control group $n=14$, while for all other groups $n=12$. From each group, six animals were selected for determining the area at risk and infarct area; the remaining six animals were selected for myocardial necrosis score determination. Any animal in which this procedure itself produced dysrhythmias, or a sustained fall in mean arterial blood pressure (MAP), to less than $70 \mathrm{mmHg}$, was discarded from study. A total of 79 rats successfully completed the above mentioned protocols and 66 rats were analyzed for arrhythmia determination. From these animals, 42 animals were analyzed for an histological investigation of myocardial infarction, and 42 rats were analyzed for area at risk (AAR) and ischemia/reperfusion determination.

\section{Arrhythmia score determination}

During the 30 minute ischemic period, occurrences of arrhythmia were scored. The numbers of ventricular premature beats (VPB), ventricular tachycardia (VT) and ventricular fibrillation (VF) are counted in the occlusion and reperfusion periods then evaluated as described by Fryer and colleagues ${ }^{18}$ and in accordance with the definitions reported in the Lambeth Conventions. ${ }^{19}$ The scoring system was assigned during ten 3 minute intervals of myocardial ischemia. Arrhythmia scores were assigned as follows: $0 \leqslant 10$ premature ventricular contractions $(\mathrm{PVCs}) / 3 \mathrm{~min}-$ ute period; $1=10$ to $50 \mathrm{PVCs} / 3$ minute period; $2 \geqslant 50$ $\mathrm{PVCs} / 3$ minute period; $3=1$ episodes of ventricular fibrillation $(\mathrm{VF}) / 3$ minute period; $4=2$ to 5 episodes of ventricular fibrillation $(\mathrm{VF}) / 3$ minute period and $5 \geqslant 4$ episodes of ventricular fibrillation/3 minute period.

\section{Measurement of AAR and infarct area (IA)}

On completion of the above mentioned protocols, six animals from each group were selected for AAR and infarct area determination. The coronary artery was re-occluded and the hearts were then immediately frozen at $-20{ }^{\circ} \mathrm{C}$ for no longer than 12 hours. The frozen hearts were then sliced from apex to base in two sections, and, after defrosting, the infarct was delineated by incubating sections at $37{ }^{\circ} \mathrm{C}$ for 15 minutes with $1 \%$ triphenyltetrazonium chloride (Sigma Chemical) in phosphate-buffered saline. The sections were fixed overnight in formal saline and then images of heart slices were captured using a scanner (HP 1300 scan jet) and analyzed for area measurement using Scion Image software (Ver 4.0.3.2). Blue areas were considered as nonischemic areas and the remaining as AAR. Any whitish portion in the AAR was considered as infarct area. AAR's were expressed as a percentage of total left ventricular area, and infarct size (IS) were expressed as a percentage of the AAR.

\section{Myocardial necrosis score}

Histological examination of the hearts was undertaken to study the severity of infarction. Necrosis produced by ischemia reperfusion injury was graded as described by Vogel and Vogel. ${ }^{20}$ After microscopic examination, grades were given as follows: grade 0 , no change; grade 1 , focal interstitial response; grade 2, focal lesions in many sections, consisting of mottled staining and fragmentation of muscle fibres; grade 3, confluent retrogressive lesions with hyaline necrosis and fragmentation of muscle fibres and sequestrating mucoid oedema; grade 4, massive infarct with occasionally acute aneurysm and mural thrombi.

\section{In vitro studies}

\section{Rat isolated right atria}

$\beta_{1}$-antagonism was studied in isolated right atria as described earlier. ${ }^{21}$ In brief, rats were killed after anesthesia 
with isoflurane and their hearts were quickly excised. Spontaneously beating right atria were set up with an initial tension of $0.3 \mathrm{~g}$. The atria were mounted in a $20 \mathrm{~mL}$ organ bath filled with Krebs physiologic saline solution (PSS) containing: $\mathrm{NaCl} 118 \mathrm{mM}$; $\mathrm{KCl} 4.7 \mathrm{mM}$ ) $\mathrm{MgSO}_{4} 1.2 \mathrm{mM}$; $\mathrm{KH}_{2} \mathrm{PO}_{4} 1.2 \mathrm{mM} ; \mathrm{CaCl}_{2} 2.5 \mathrm{mM}$; $\mathrm{NaHCO}_{3} 25 \mathrm{mM}$; disodium EDTA (ethylenediaminetetraacetic acid) $0.03 \mathrm{mM}$ and glucose $11.1 \mathrm{mM}$. The solution was kept at $37^{\circ} \mathrm{C} \pm 1{ }^{\circ} \mathrm{C}$ and was continuously oxygenated. The physiologic saline solution (PSS) contained prazosin $(1 \mu \mathrm{g})$ to block alpha adrenoceptors. Spontaneous response of atria were recorded by connecting the upper end to the force transducer (T-305) connected to student physiograph (Bio-Devices, Ambala, India) at a paper speed of $50 \mathrm{~mm} / \mathrm{second}$.

The resting tension was maintained at $0.2 \mathrm{~g}$ during a 30 minutes equilibration period. Cumulative concentration response curves (CRCs), for increase in sinus rate (positive chronotropic effect) of isoprenaline were constructed by addition of $\log$ increment doses of isoprenaline at an interval of 3 minutes. Sinus rate was assessed 15 seconds after the addition of each successive concentration of isoprenaline for 1 minute. For assessment of antagonist activity, response of the atrium to isoprenaline dose was determined in presence of PP-36 or standard drugs. Antagonists were added 30 minutes before the addition of agonists. The number of experiments was 6 for all the experiments.

\section{Isolated guinea pig tracheal ring}

$\beta_{2}$-antagonism was studied in guinea-pig isolated tracheal rings as described earlier. ${ }^{22}$ Guinea-pig tracheal rings were carefully isolated and immersed in Krebs PSS containing: $\mathrm{NaCl} 118 \mathrm{mM}$; KCl 4.7 mM; $\mathrm{MgSO}_{4} 1.2 \mathrm{mM}$; $\mathrm{KH}_{2} \mathrm{PO}_{4}$ $1.2 \mathrm{mM} ; \mathrm{CaCl}_{2} 2.5 \mathrm{mM}$; $\mathrm{NaHCO}_{3} 25 \mathrm{mM}$, disodium EDTA $0.03 \mathrm{mM}$ and glucose $11.1 \mathrm{mM}$ ) The solution was kept at $37{ }^{\circ} \mathrm{C} \pm 1{ }^{\circ} \mathrm{C}$ and was continuously oxygenated. The $\mathrm{pH}$ of the solution was maintained at 7.4. The tracheal rings were cautiously cleaned of unnecessary adipose and connective tissues under a dissecting microscope so that the smooth muscles were not damaged. Subsequently, tracheal cartilage containing smooth muscles were cut into 2-mm long sections. Preparations were suspended using stainless steel hooks (outer diameter, $200 \mu \mathrm{m}$ ) in a $20-\mathrm{mL}$ organ bath. Tension changes of the tracheal preparation were isotonically recorded with a force-displacement transducer (T-305) connected to physiograph (Bio-Devices) at a paper speed of $0.25 \mathrm{~mm} /$ second. Relaxant action of agonists was determined by measuring relaxation of carbachol induced contraction evoked by addition of the agonists. Initially
$150 \mathrm{nM}$ carbachol was added after an equilibration period. Carbachol induced contractions were allowed to stabilize for 15 minutes followed by a 30 minute wash. Tissues were then incubated with appropriate concentrations of antagonist for 30 minutes with control tissues receiving saline treatment. The tissues were then contracted again with carbachol $(150 \mathrm{mM})$ and allowed to stabilize. CRCs to isoprenaline were constructed by cumulative addition (0.5 log unit increments) to carbachol contracted strips at 2 minute interval until the tissue relaxes and reaches plateau. The number of experiments was 6 for all the experiments.

\section{Isolated rat colon}

Male Wistar rats (200-250 g) were fasted overnight. On the next day they were killed under anesthesia with isoflurane and distal colon (6 cm in length) was removed as described earlier ${ }^{23}$ and cleared of from any fecal material by gently squeezing the colon with the fingers. Portions of colon were then immediately placed in cool Krebs PSS. Segments $(3 \mathrm{~cm})$ of colon were mounted with care taken not to occlude the lumen, in $50 \mathrm{~mL}$ organ baths (Bio-Devices) containing $40 \mathrm{~mL}$ of Krebs solution, at $37 \pm 1{ }^{\circ} \mathrm{C}$ bubbled continuously with $95 \%$ oxygen under an initial tension of $1 \mathrm{~g}$. The composition of the Krebs PSS was as follows: $\mathrm{NaCl}$ $118 \mathrm{mM}$; $\mathrm{KCl} 4.7 \mathrm{mM}$ ) $\mathrm{NaHCO}_{3} 25 \mathrm{mM}, \mathrm{CaCl}_{2} 2.5 \mathrm{mM}$, $\mathrm{KH}_{2} \mathrm{PO}_{4} 1.2 \mathrm{mM}, \mathrm{MgSO}_{4} 1.2 \mathrm{mM}$ and glucose $11.1 \mathrm{mM}$. Additionally, Krebs PSS contained $30 \mu \mathrm{M}$ of ascorbic acid, $30 \mu \mathrm{M}$ of the sodium salt of EDTA to prevent oxidation of catecholamine and $1 \mu \mathrm{M}$ of prazosin hydrochloride to remove any possible contribution from $\alpha$ adrenoreceptors. Tissues were allowed to equilibrate for at least 30 minutes before experimental procedures were begun. Relaxant action of agonists were determined by measuring relaxation of $\mathrm{KCl}$ induced contraction evoked by addition of the agonists. Initially $50 \mathrm{mM} \mathrm{KCl}$ was added after equilibration period. $\mathrm{KCl}$ induced contractions were allowed to stabilize for 15 minutes followed by 30 minute wash. Tissues were again contracted with a submaximal contraction of $\mathrm{KCl}$ $(30 \mathrm{mM})$ and washed for 30 minutes. Tissues were then incubated with appropriate concentrations of antagonist for 30 minutes with control tissues receiving saline treatment. The tissues were then contracted again with $\mathrm{KCl}(30 \mathrm{mM})$ and allowed to stabilize. CRCs to isoprenaline were constructed by cumulative addition ( $0.5 \mathrm{log}$ unit increments) to $\mathrm{KCl}$ contracted strips at 2 minute intervals until the tissue relaxes and reaches plateau. The number of experiments was 6 for all the experiments. 


\section{Statistics}

In vivo studies

All values of parametric measures were expressed as mean \pm standard error of mean (SEM). For hemodynamic parameters, one-way analysis of variance followed by a Dunnett post-hoc test was used. For nonparametric measures, arrhythmia and necrosis scores, Kruskal-Wallis test followed by a Dunn's post-hoc test were used. All these statistical calculations were performed by using Instat ${ }^{\circledR}$ (GraphPad Software Inc., San Diego, CA, USA). A $P$ value of less than 0.05 was considered statistically significant.

\section{In vitro studies}

In the in vitro studies, mean concentration curves of isoprenaline were analyzed using nonlinear regression (Graph Pad Prism, version 4.0; GraphPad Software Inc. The effective concentration $\left(\mathrm{EC}_{50}\right.$ ) and $\mathrm{pEC}_{50}$ (negative logarithm of $\mathrm{EC}_{50}$ ) values of isoprenaline were obtained with and without the presence of antagonist. Concentration ratios (CR) were determined from the $\mathrm{EC}_{50}$ values. The plot of $\log (\mathrm{CR}-1)$ versus log [antagonist] was analyzed by linear regression. Antagonism was considered to be competitive in nature if the slope of the regression line was not significantly different from the equation: $\mathrm{pA}_{2}=[\log (\mathrm{CR}-1)-\log$ molar concentration of antagonist]. In cases, where the slope or regression line significantly differed from unity, the value obtained from the above equation was the $\mathrm{pK}_{\mathrm{B}}$ rather than the $\mathrm{pA}_{2}$ value. A statistically significant difference between two means was analyzed using repeated two way analysis of variance followed by the Tukey test, where comparison was made to the same control group. For comparing unpaired data twoway analysis of variance followed by the Dunnett test was performed. $P<0.05$ was considered significant.

\section{Results}

\section{Acute I.V. toxicity study}

The lethal dose $\left(\mathrm{LD}_{50}\right)$ of PP-36 was found to be $98.11 \mathrm{mg} / \mathrm{kg}$. This intravenous $\mathrm{LD}_{50}$ was quiet high when compared to the effective dose of PP-36 (effective dose of PP-36 was less than $10 \%$ of the $\left.\mathrm{LD}_{50}\right)$.

\section{Cardioprotective effect of PP-36 against ischemia/reperfusion injury in rats}

Hemodynamic parameters, heart rate (HR), MAP, and pressure rate index (PRI) are summarized in Table 1. These parameters were determined at; baseline; 15 minutes of coronary artery occlusion; and 120 minutes of reperfusion. Before left anterior descending artery (LAD) occlusion HR, MAP and PRI values were in the same range in rats treated with the vehicle, PP-36 (1.0, 3.0 and $6.0 \mathrm{mg} / \mathrm{kg})$ and atenolol $(0.3$ and $1 \mathrm{mg} / \mathrm{kg}$ ). Following LAD occlusion the MAP values of the animals in the experimental groups consistently and abruptly fell (peak effect at 5 minutes) and then progressively recovered within 30 minutes to the levels of $80-85 \mathrm{mmHg}$. Cardiac mechanic parameters MAP, PRI of the animals treated with PP-36 (at 1.0, 3.0 and $6.0 \mathrm{mg} / \mathrm{kg}$ ) and atenolol (at 0.3 and $1 \mathrm{mg} / \mathrm{kg}$ ) were not found to be significantly different. However, HR was found to be significantly different $(P<0.01)$ from the vehicle group in case of atenolol $(1 \mathrm{mg} / \mathrm{kg})$ at 15 minute ischemia and after 2 hour reperfusion. All other HR values were not found significantly different.

\section{Mortality}

In the vehicle-treated group mortality was found to be high (17\%), with 3 out of 17 animals dying during 30 minutes ischemia period. Groups treated with PP-36 (3 and $6 \mathrm{mg} / \mathrm{kg}$ ) and atenolol (1 mg/kg) showed no mortality; however, in the

Table I Hemodynamics

\begin{tabular}{|c|c|c|c|c|c|c|c|c|c|c|}
\hline \multirow[t]{2}{*}{ Group } & \multirow[t]{2}{*}{$\mathbf{n}$} & \multicolumn{3}{|l|}{ Baseline } & \multicolumn{3}{|c|}{ I5-min Ischemia } & \multicolumn{3}{|c|}{ 2-h reperfusion } \\
\hline & & HR & MAP & PRI & HR & MAP & PRI & HR & MAP & PRI \\
\hline Sham & 6 & $318 \pm 10$ & $118 \pm 3$ & $35 \pm 1$ & $329 \pm 15$ & $103 \pm 6$ & $31 \pm 1$ & $311 \pm 7$ & $93 \pm 3$ & $29 \pm 1$ \\
\hline Control & 19 & $321 \pm 5$ & $105 \pm 4$ & $34 \pm 2$ & $374 \pm 7$ & $69 \pm 5$ & $26 \pm 2$ & $365 \pm 2$ & $76 \pm 8$ & $29 \pm 2$ \\
\hline $\begin{array}{l}\text { PP-36 } \\
(1.0 \mathrm{mg} / \mathrm{kg})\end{array}$ & 12 & $294 \pm 22$ & $98 \pm 9$ & $29 \pm 3^{*}$ & $375 \pm 17$ & $68 \pm 4$ & $25 \pm 2$ & $353 \pm 6$ & $77 \pm 5$ & $27 \pm 1$ \\
\hline $\begin{array}{l}\text { PP-36 } \\
(3.0 \mathrm{mg} / \mathrm{kg})\end{array}$ & 12 & $286 \pm 12^{*}$ & $97 \pm 5$ & $28 \pm 2^{* *}$ & $362 \pm 17$ & $70 \pm 4$ & $25 \pm 3$ & $34 I \pm 23^{* *}$ & $79 \pm 6$ & $27 \pm 1$ \\
\hline $\begin{array}{l}\text { PP-36 } \\
(6.0 \mathrm{mg} / \mathrm{kg})\end{array}$ & 12 & $274 \pm 17 * *$ & $95 \pm 6 *$ & $26 \pm 3 * *$ & $345 \pm 11 * *$ & $7 I \pm 5$ & $25 \pm 2$ & $332 \pm 13^{* *}$ & $81 \pm 4$ & $27 \pm 2$ \\
\hline $\begin{array}{l}\text { Atenolol } \\
\text { (1.0 mg/kg) }\end{array}$ & 12 & $263 \pm 12 * *$ & $97 \pm 9 * *$ & $24 \pm 3^{* *}$ & $328 \pm 19 * *$ & $78 \pm 5$ & $23 \pm 3$ & $314 \pm 18 * *$ & $88 \pm 9$ & $27 \pm 2$ \\
\hline
\end{tabular}

Notes: Values given as mean \pm standard error of mean. Heart rate (HR, beats/min), Mean arterial pressure (MAP, mm Hg), Pressure rate index (PRI, mm Hg · min $\left.{ }^{-1} \cdot 1000^{-1}\right)$ $* P<0.05$, $* * P<0.0$ I versus control. 
group treated with PP-36 $(1 \mathrm{mg} / \mathrm{kg}) 1$ out of the 12 animals died during 30 minutes ischemia period which represented $8 \%$ mortality.

\section{AAR and IS}

No significant differences were found in any group versus control for AAR expressed as a percentage of the left ventricle (LV; Table 2), which indicates that all groups were subjected to a similar degree of ischemic insult. Control animals $(n=6)$ exhibited an IS/AAR of $44.9 \pm 5.1$. PP-36 (6 mg/kg, $\mathrm{n}=6)$ and atenolol $(1 \mathrm{mg} / \mathrm{kg}, \mathrm{n}=6)$ reduced IS/AAR significantly $(38.9 \pm 3.2$ and $37.6 \pm 2.3$, respectively). Similarly PP-36 $(6 \mathrm{mg} / \mathrm{kg}, \mathrm{n}=6)$ and atenolol $(1 \mathrm{mg} / \mathrm{kg}, \mathrm{n}=6)$ reduced
IS/LV significantly $(22.3 \pm 2.9$ and $21.7 \pm 1.6$, respectively $)$ compared with the control $(28.7 \pm 3.7)$.

\section{Arrhythmia and necrosis score}

The effects of PP-34 and atenolol on myocardial arrhythmia in anesthetized rats are shown in Figure 2. This summarizes incidences of cardiac arrhythmia during 3 minute intervals in the control animals and animals treated with the PP-36 and atenolol for 30 minutes of ischemia. LAD occlusion and reperfusion caused consistent ventricular ectopic activity associated with a high degree of mortality in vehicle-treated control group. The arrhythmias score in vehicle-treated animals $(n=9)$ was $14.17 \pm 1.83$ (Table 3 ). The incidence of arrhythmias was
A

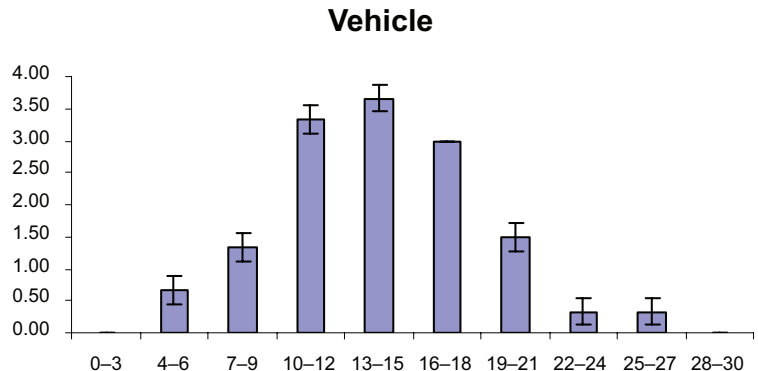

C

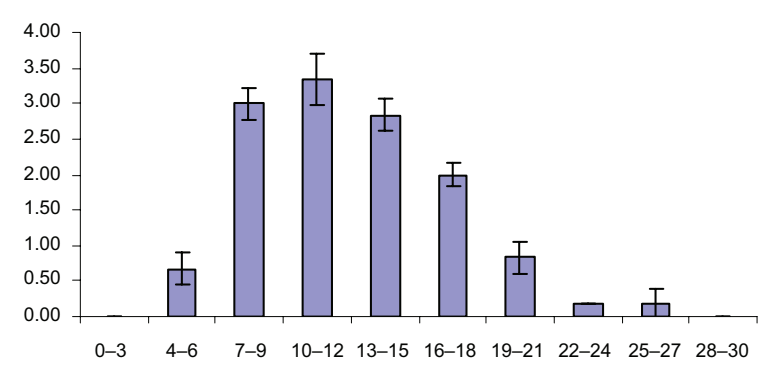

B PP $36(1 \mathrm{mg} / \mathrm{kg})$

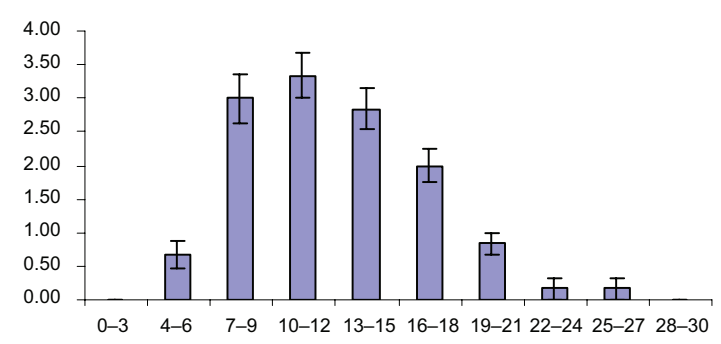

D

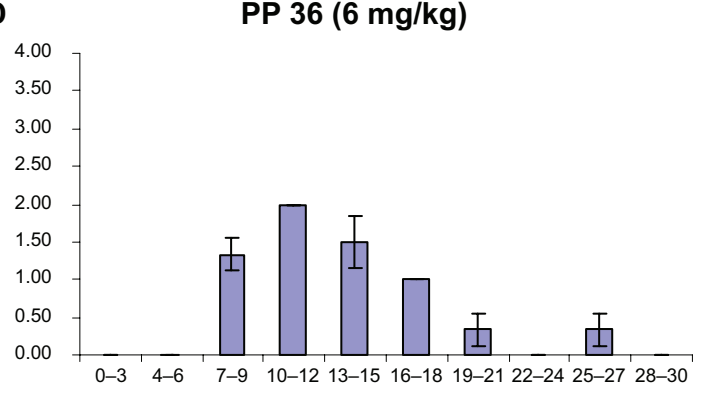

E

Atenolol (1 mg/kg)

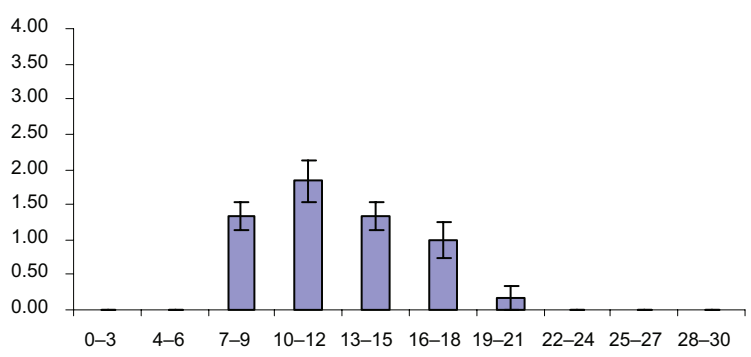

Figure 2 Incidence of cardiac arrhythmia during 3 minute intervals in control animals (A) and animals treated with the PP-36[(B) I, (C) 3 and (D) 6 mg/kg] and atenolol [(E) $\mathrm{I} \mathrm{mg} / \mathrm{kg}]$. X axis = Arrhythmia score, $\mathrm{Y}$ axis = Minutes (in 3 minute interval) of myocardial ischemia. 
Table 2 Effects of PP-36 and atenolol on total arrhythmia score during ischemia and myocardial necrosis score after reperfusion

\begin{tabular}{lll}
\hline Group & $\begin{array}{l}\text { Total arrhythmia } \\
\text { score }\end{array}$ & $\begin{array}{l}\text { Myocardial } \\
\text { necrosis score }\end{array}$ \\
\hline Control & $14.17 \pm 1.83$ & $3.00 \pm 0.00$ \\
PP-36 $(1 \mathrm{mg} / \mathrm{kg})$ & $13.0 \pm 1.90$ & $2.67 \pm 0.21$ \\
PP-36 $(3 \mathrm{mg} / \mathrm{kg})$ & $10.50 \pm 1.38$ & $2.33 \pm 0.24$ \\
PP-36 $(6 \mathrm{mg} / \mathrm{kg})$ & $6.50 \pm 0.55^{*}$ & $2.17 \pm 0.16^{*}$ \\
Atenolol $(\mathrm{I} \mathrm{mg} / \mathrm{kg})$ & $5.67 \pm 0.82^{* *}$ & $1.67 \pm 0.21^{* *}$ \\
\hline
\end{tabular}

Notes: $* P<0.05, * * P<0.01$ versus control.

significantly reduced via the administration of PP-36, $6 \mathrm{mg} / \mathrm{kg}$ $(6.33 \pm 0.55, \mathrm{n}=6, P<0.05)$ and atenolol $1 \mathrm{mg} / \mathrm{kg}(5.67 \pm$ $0.82, \mathrm{n}=6, P<0.05)$. However, PP-36 (1 and $3 \mathrm{mg} / \mathrm{kg})$ produced a smaller, yet insignificant, numbers of arrhythmias versus the vehicle-treated group (Figure 2, Table 3).

\section{In vitro studies}

The CRC's for isoprenaline alone and in the presence of PP-36 and atenolol on different tissues are shown in Figure 3. Both PP-36 and atenolol shifted the CRCs of isoprenaline towards the right, with a change in the $\mathrm{EC}_{50}$ values for isoprenaline in all three tissue preparations (Figure 3). The Schield plot yielded a line with a slope close to unity for the test and standard antagonists in rat isolated atria and guinea-pig tracheal ring preparation, indicating that the antagonist, were competitive in nature for $\beta_{1}$ and $\beta_{2}$ receptor subtype. However, the slope of the Schield plot was significantly different from unity for the test and standard drugs on rat isolated colon, indicating noncompetitive antagonism of $\beta_{3}$-adrenoceptor (Table 4). The $\mathrm{pA}_{2}$ values of PP-36 and atenolol are shown in Table 4. The $\mathrm{pA}_{2}$ value for the $\beta_{1}$-adrenoceptor was in order of Atenolol $>$ PP-36.

\section{Discussion}

The hemodynamic effects of treatment with $\beta$ blockers, in patients with heart failure, are a lower heart rate, a drop in systolic blood pressure, a reduction of left ventricular

Table 3 Effects of PP-36 and atenolol on myocardial infarct size

\begin{tabular}{lllll}
\hline Group & $\mathbf{n}$ & $\%$ Inf/LV & \% Inf/AAR & \% AAR/LV \\
\hline Control & 6 & $27.7 \pm 3.9$ & $44.9 \pm 5.1$ & $56.8 \pm 3.4$ \\
PP-36 (I mg/kg) & 6 & $28.0 \pm 4.0$ & $44.1 \pm 3.2$ & $58.3 \pm 2.9$ \\
PP-36 (3 mg/kg) & 6 & $25.1 \pm 3.6$ & $40.3 \pm 2.9$ & $57.5 \pm 3.1$ \\
PP-36 $(6 \mathrm{mg} / \mathrm{kg})$ & 6 & $22.3 \pm 2.9 *$ & $38.9 \pm 3.2^{*}$ & $58.0 \pm 2.8$ \\
Atenolol $(\mathrm{I} \mathrm{mg/kg)}$ & 6 & $21.7 \pm 1.6 *$ & $37.6 \pm 2.3 * *$ & $53.6 \pm 4.2$ \\
\hline
\end{tabular}

Notes: \% Infarct size (Inf) left ventricle (LV) and \% Inf area at risk (AAR) after 30 minutes of left anterior descending coronary artery occlusion and 2 hours of reperfusion compared with vehicle. The mean areas at risk (\% AAR/LV) were not significantly different, indicating that the degree of the ischemic insult was similar. $* P<0.05$, ** $P<0.01$ versus control.

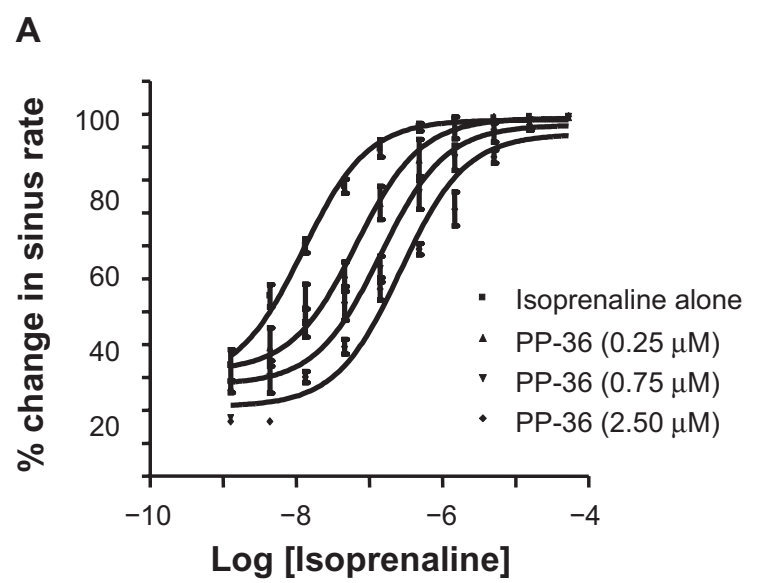

B

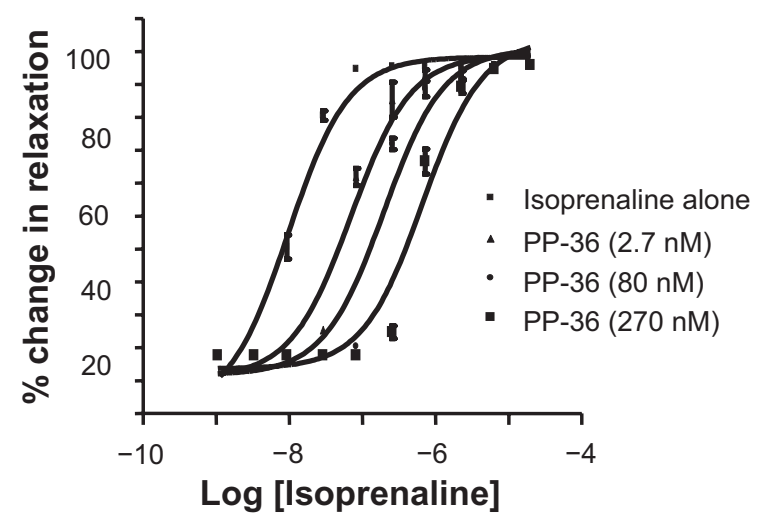

C

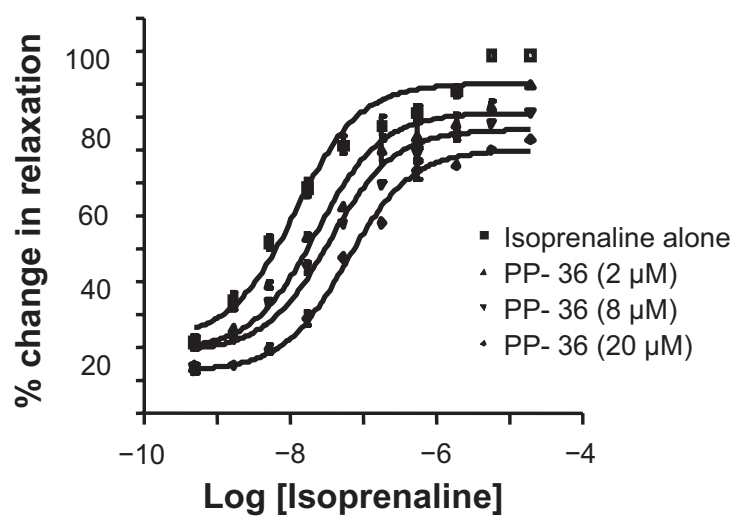

Figure 3 Antagonism of isoprenaline response by PP-36 in different tissue. (A) Rat right atria; (B) Guinea-pig trachea; (C) Rat distal colon.

end-diastolic pressure (LVEDP) and an increase in ejection fraction. ${ }^{24-26}$ Coronary artery ligation in rats is one of the most commonly used models to study the efficiency of new drugs for their cardioprotective effect in myocardial infarction. ${ }^{27} \mathrm{In}$ this study, pretreatment with PP-36 reduced the arrhythmic score, infarct area and mortality against ischemic/reperfusion injury. $\beta$ blockers are a class of drugs that decrease myocardial oxygen demand and protect the heart against ischemia. These 
Table 4 Potencies of PP-36 and atenolol on isolated tissue preparations. Values in bracket are slope of Schild plot

\begin{tabular}{|c|c|c|c|}
\hline \multirow[t]{2}{*}{ Group } & $\beta_{1}$ & $\beta_{2}$ & $\beta_{3}$ \\
\hline & $\begin{array}{l}\text { pA }_{2} \text { value } \\
\text { (slope) Right } \\
\text { atrium }\end{array}$ & $\begin{array}{l}\mathrm{pA}_{2} \text { value (slope) } \\
\text { Guinea-pig } \\
\text { trachea }\end{array}$ & $\begin{array}{l}\mathrm{pA}_{2} \text { value } \\
\text { (slope) Rat } \\
\text { distal colon }\end{array}$ \\
\hline \multirow[t]{2}{*}{ PP-36 } & $6.904 \pm 0.190$ & $6.44 \pm 0.129$ & $5.773 \pm 0.129$ \\
\hline & $(0.72 \pm 0.03)$ & $(\mathrm{I} .25 \pm 0.0 \mathrm{I})$ & $(0.64 \pm 0.04)$ \\
\hline \multirow[t]{2}{*}{ Atenolol } & $7.16 \pm 0.09$ & $5.57 \pm 0.06$ & $4.62 \pm 0.33$ \\
\hline & $(1.18 \pm 0.10)$ & $(0.99 \pm 0.11)$ & $(0.15 \pm 0.05)$ \\
\hline
\end{tabular}

effects primarily result from the ability of $\beta$ blockers to decrease heart rate, myocardial contractility and wall tension. ${ }^{28}$ Other beneficial effects of these compounds in myocardial ischemia are antiarrhythmic actions. ${ }^{29,30}$ The reduction of heart rate is one of the actions specific to the class of compounds that reduce myocardial oxygen consumption. The major cardioprotective effect of PP-36 may have resulted from a decrease in heart rate, myocardial contractility and antiarrhythmic actions. The lowering of the heart rate, blood pressure and pressure rate index suggest that PP-36 possibly reduced the myocardial oxygen consumption. Earlier studies ${ }^{31}$ have shown that the $\beta$-adrenoceptor blockade significantly reduced the incidence of ventricular fibrillation in rats. $\beta$-adrenergic stimulation increases the magnitude of the $\mathrm{Ca}^{2+}$ current and slows its inactivation, increases the magnitude of repolarizing $\mathrm{K}^{+}$and $\mathrm{Cl}^{-}$current, ${ }^{32,33}$ increases pacemaker current (thereby increasing sinus rate), and under pathophysiological conditions can increase both delayed afterdepolarization and early after depolarization mediated arrhythmias. Thus, blockage of $\beta$ stimulation through $\beta$-adrenoceptor antagonist can reduce the severity of arrhythmia in myocardial patients. The result of this study showed that pretreatment with PP-36 reduced the arrhythmia score, and the incidence and the severity of arrhythmia.

Tissue experiments were conducted to assess antagonist potency of PP-36 towards different $\beta$-adrenoceptor subtypes. Isoprenaline is a synthetic catecholamine derived from the noradrenaline by the substitution of an isopropyl group on the nitrogen atom of the aliphatic side chain. Amongst the beta-active sympathomimetics isoprenaline is most active and it acts exclusively on the beta adrenoceptors. It is a nonselective beta agonist and has a little effect on alpha-receptors. ${ }^{34}$ The antagonistic property of PP-36 was checked against isoprenaline induced agonistic action. The $\mathrm{pA}_{2}$ values from the tissue in-vitro preparations indicated that the antagonist potency was in the order of atenolol $>$ PP-36 to Beta 1 adrenoceptor subtype and PP-36 > atenolol to Beta 2 and Beta 3 adrenoceptor subtypes. Beta-receptor antagonists have prominent effects on the heart and are very valuable in the treatment of angina and chronic heart failure and following myocardial infarction. Slowed atrioventricular conduction with an increased PR interval is a related result of adrenoceptor blockade in the atrioventricular node. In the vascular system, $\beta$-receptor blockade opposes $\beta_{2}$-mediated vasodilation. This may acutely lead to a rise in peripheral resistance from unopposed $\beta$-receptor-mediated effects as the sympathetic nervous system discharges in response to lowered blood pressure due to the fall in cardiac output. Nonselective and $\beta_{1}$-blocking drugs antagonize the release of rennin caused by the sympathetic nervous system.

Though PP-36 is a nonselective beta blocker and it could be a potential limitation, recent studies suggested the beneficial effect of $\beta_{2}$-adrenergic blockade on vascular events in patients with acute coronary syndrome and heart failure. ${ }^{35-37}$ Beta blockers with $\beta_{2}$-adrenergic inhibitory effects could reduce sympathetic activation and the associated prothrombotic activity, and consequently, the number of vascular events. ${ }^{38}$ PP-36 showed a reduction in infarct area with no mortality therefore there may be a possible involvement of additional $\beta_{2}$-adrenoceptor blocked in its cardioprotective action. Previous studies have suggested that the release of norepinephrine is partly regulated by prejunctional $\beta_{2}$ adrenergic receptors. This implies that $\beta_{1}+\beta_{2}$ blockers have a specific sympathoinhibitory effect that is less prominent in $\beta_{1}$ blockers. This suggests that suppression of $\beta_{2}$ adrenergic receptor addition to $\beta_{1}$ receptor may be more effective in reducing vascular events in patients with acute coronary syndrome and heart failure. ${ }^{35-37}$

Evidence from other studies, the order of $\mathrm{pA}_{2}$ value ratio from this study and the weak antioxidant property of PP-36 (data not presented here) suggest that the $\beta$-adrenoceptor blocking activity of PP-36 may be one reason for the cardioprotective effect against ischemia reperfusion injury in rats. Additionally the duration of action was found to be more with PP-36 in normal rats (data not present here).

In conclusion PP-36 exhibited potent $\beta$-adrenoceptor antagonistic activity which is responsible for its antiarrhythmic and cardioprotective effects against ischemia/reperfusion injury in the rats. The LD50 of PP-36 is relatively high and effective dose is relatively safe.

\section{Disclosures}

The authors report no conflicts of interest relevent to this research.

\section{References}

1. Anderson GF, Chu E. Expanding priorities - confronting chronic disease in countries with low income. N Engl J Med. 2007;356(3):209-211. 
2. WHO study group. World Health Organization (WHO)/International Society of Hypertension (ISH) statement on management of hypertension. J Hypertens. 2003;21(11):1983-1992.

3. Murray CJ, Lopez AD. Global Comparative Assessments in the Health Sector. Geneva, Switzerland: World Health Organization. 1994.

4. Beaglehole R. Global cardiovascular diseases prevention: time to get serious. Lancet. 2001;358:661-663.

5. Neaton JD, Grimm RH, Princas RJ, et al. Treatment of mild hypertension study. Final results. JAMA. 1993;270:713-724.

6. Messerli FH, Bangalore S, Yao SS, Steinberg JS. Cardioprotection with beta-blockers: myths, facts and Pascal's wager. J Intern Med. 2009;266(3):232-241.

7. Joint national Committee on prevention, evaluation and treatment of high blood pressure. The sixth report. Arch Intern Med. 1997;157:2413-2446.

8. Ramsay LE, Williams B, Johnston GD, et al. British Hypertension Society guidelines for hypertension management 1999: summary. BMJ. 1999;319:630-635.

9. Tamargo J, Delpón E. Optimization of beta-blockers' pharmacology. J Cardiovasc Pharmacol. 1990;16(Suppl 5):S10-S18.

10. Rang HP, Dale MM, Ritter JM. Pharmacology. 6th ed. New York, NY: Churchill Livingstone: 2007:180-182.

11. Bhatt LK, Nandakumar K, Bodhankar SL, et al. Beta-blocking activity of PP-34, a newly synthesized aryloxypropanolamine derivative, and its cardioprotective effect against ischemia/reperfusion injury in laboratory animals. J Pharm Pharmacol. 2007;59(3):429-436.

12. Nandkumar K, Bansal SK, Singh R, et al. Study of $\beta$-adrenoceptor antagonistic activity of DPJ 904 in rats. Pharmacology. 2005;74:1-5.

13. Nandkumar K, Bansal SK, Singh R, et al. Selective $\beta_{1}$-adrenoreceptor blocking activity of newly synthesized acyl amino-substituted aryloxypropanolamine derivatives, DPJ 955 and DPJ 890, in rats. $J$ Pharm Pharmacol. 2005;57:1-6.

14. Jindal DP, Coumar MS, Bruni G, Massarelli P. Synthesis and $\beta_{1}$, $\beta_{2}$-adrenergic receptor binding studies of 4-acyl amino - substituted phenoxypropanolamine and 5-acyl amino - substituted naphthyloxypropanolamine derivatives. Arzneimittelforschng. 2002;52(9):654-663.

15. Jindal DP, Coumar MS, Nandakumar K, et al. Synthesis, beta adrenoreceptor blocking activity and beta receptor binding affinities of1-substituted-3-(2-isopropyl-5-methyl-phenoxy)-propan-2-ol oxalates. Il Farmaco. 2003;58:557-562.

16. Burke SG, Wainwright CL, Vojnovic I, Warner T, Watson DG, Furman BL. The effect of NCX4016 [2-acetoxy-benzoate 2-(2-nitroxymethyl)phenyl ester] on the consequences of ischemia and reperfusion in the streptozotocin diabetic rat. J Pharmacol Exp Ther. 2006;316(3):1107-1114

17. Lawson CS, Coltart DJ, Hearse DJ. Dose-dependency and temporal characteristics of protection by ischaemic preconditioning against ischemia-induced arrhythmias in rat hearts. $J$ Mol Cell Cardiol. 1993;25:1391-1402.

18. Fryer RM, Hsu AK, Hiroshi N, Gross Garrett J. Opioid induced cardioprotection against myocardial infarction and arrhythmias: mitochondrial versus sarcolemmal ATP-sensitive potassium channels. J Pharmacol Exp Ther. 2000;294:451-457.

19. Walker MJ, Curtis MJ, Hearse DJ, et al. The Lambeth Conventions: guidelines for the study of arrhythmias in ischemia infarction, and reperfusion. Cardiovasc Res. 1988;22:447-455.

20. Vogel GH, Vogel WH, Scholkens BA, Sandow J, Muller G, Vogel WF, editors. Drug Discovery and Evaluation: Pharmacological assays. 2nd ed Berlin, Germany: Springer-Verlag; 2002:108-109.

Journal of Experimental Pharmacology

\section{Publish your work in this journal}

The Journal of Experimental Pharmacology is an international, peerreviewed, open access journal publishing original research, reports, reviews and commentaries on all areas of laboratory and experimental pharmacology. The manuscript management system is completely online and includes a very quick and fair peer-review system.
21. Dinçer UD, Onay A, Ari N, Ozçelikay AT, Altan VM. The effects of diabetes on beta-adrenoceptor mediated responsiveness of human and rat atria. Diabetes Res Clin Pract. 1998;40(2):113-122.

22. Suzuki H, Ueno A, Takei M, Sindo K, Miura T, Sakakibara M, Higa T, Fukamachi $\mathrm{H}$. Tracheal relaxing effects and beta2 adrenoceptor selectivity of S1319, a novel sponge-derived bronchodilator agent, in isolated guinea-pig tissues. Br J Pharmacol. 1999;128(3):716-720.

23. Oriowo MA, Chapman H, Kirkham DM, Sennitt MV, Ruffolo RR Jr, Cawthorne MA. The selectivity in vitro of the stereoisomers of the beta-3 adrenoceptor agonist BRL 37344. J Pharmacol Exp Ther. 1996;277(1):22-27.

24. Krum H, Sacker-Bernstein JD, Goldsmith RL, et al. Double-bind, placebocontrolled study of the long-term efficacy of carvedilol in patients with severe chronic heart failure. Circulation. 1995;92:1499-1506.

25. Weber K, Bohmeke T, Van der Does R, Taylor SH. Hemodynamic differences between metoprolol and carvedilol in hypertensive patients. Am J Hypertens. 1998;11:614-617.

26. Eichhorn EF, Heesch CM, Risser RC, Marcoux L, Hatfield B. Predictors of systolic and diastolic improvement in patients with dilated cardiomyopathy treated with metoprolol. J Am Coll Cardiol. 1995;25: $154-162$.

27. Vidavalur R, Swarnakar S, Thirunavukkarasu M, Samuel SM, Maulik N. Ex vivo and in vivo approaches to study mechanisms of cardioprotection targeting ischemia/reperfusion (i/r) injury: useful techniques for cardiovascular drug discovery. Curr Drug Discov Technol. 2008;5(4):269-278.

28. Feuerstein GZ, Bril A, Ruffolo RR. Protective effect of carvedilol in the myocardium. Am J Cardiol. 1997;80(11A):41L-45L.

29. Zicha S, Tsuji Y, Shiroshita-Takeshita A, Nattel S. Beta-blockers as antiarrhythmic agents. Handb Exp Pharmacol. 2006; (171):235-266.

30. Dorian P. Antiarrhythmic action of beta-blockers: potential mechanisms. J Cardiovasc Pharmacol Ther. 2005;10(Suppl 1):S15-S22.

31. Bourque D, Daoust R, Huard V, Charneux M. Beta-Blockers for the treatment of cardiac arrest from ventricular fibrillation? Resuscitation. 2007;75(3):434-444.

32. Hume JR, Harveyy RD. Chloride conductance pathway in heart. Am. J. Physiol. 1991;261:C399-C412.

33. Sanguinetti MC, Jurkiewicz NK, Scott A, Siegl PK. Isoproterenol antagonizes prolongation of refractory period by the classIII antiarrhythmic agent E-4031 in guinea pig myocytes. Mechanism of action. Circ Res. 1991;68:77-84.

34. Barar FSK. Adrenergic agents. 7th ed. In: Barar FSK, editor. Essential of Pharmacotherapeutics. New Delhi, India: S. Chand and Company Ltd; 2004:207-217.

35. Azevedo ER, Kubo T, Mak S, et al. Nonselective versus selective betaadrenergic receptor blockade in congestive heart failure: differential effects on sympathetic activity. Circulation. 2001;104:2194-2199.

36. Herman RB, Jesudason PJ, Mustafa AM, et al. Differential effects of carvedilol and atenolol on plasma noradrenaline during exercise in humans. Br J Clin Pharmacol. 2003;55:134-138.

37. Kohno T, Yoshikawa T, Yoshizawa A, et al. Carvedilol exerts more potent antiadrenergic effect than metoprolol in heart failure. Cardiovasc Drugs Ther. 2005;19:347-355.

38. de Peuter OR, Lussana F, Peters RJ, Büller HR, Kamphuisen PW. A systematic review of selective and non-selective beta blockers for prevention of vascular events in patients with acute coronary syndrome or heart failure. Neth J Med. 2009;67(9):284-94.

\section{Dovepress}

Visit http://www.dovepress.com/testimonials.php to read real quotes from published authors. 